\title{
Founder mutations characterise the mutation panorama in 200 Swedish index cases referred for Long QT syndrome genetic testing
}

Eva-Lena Stattin ${ }^{1 *}$, Ida Maria Boström¹, Annika Winbo², Kristina Cederquist', Jenni Jonasson', Björn-Anders Jonsson', Ulla-Britt Diamant ${ }^{3}$, Steen M Jensen ${ }^{3}$, Annika Rydberg ${ }^{2}$ and Anna Norberg ${ }^{1}$

\begin{abstract}
Background: Long QT syndrome (LQTS) is an inherited arrhythmic disorder characterised by prolongation of the QT interval on ECG, presence of syncope and sudden death. The symptoms in LQTS patients are highly variable, and genotype influences the clinical course. This study aims to report the spectrum of LQTS mutations in a Swedish cohort.

Methods: Between March 2006 and October 2009, two hundred, unrelated index cases were referred to the Department of Clinical Genetics, Umeå University Hospital, Sweden, for LQTS genetic testing. We scanned five of the LQTS-susceptibility genes (KCNQ1, KCNH2, SCN5A, KCNE1, and KCNE2) for mutations by DHPLC and/or sequencing. We applied MLPA to detect large deletions or duplications in the KCNQ1, KCNH2, SCN5A, KCNE1, and KCNE2 genes. Furthermore, the gene RYR2 was screened in 36 selected LQTS genotype-negative patients to detect cases with the clinically overlapping disease catecholaminergic polymorphic ventricular tachycardia (CPVT).

Results: In total, a disease-causing mutation was identified in 103 of the 200 (52\%) index cases. Of these, altered exon copy numbers in the KCNH2 gene accounted for $2 \%$ of the mutations, whereas a RYR2 mutation accounted for $3 \%$ of the mutations. The genotype-positive cases stemmed from 64 distinct mutations, of which $28 \%$ were novel to this cohort. The majority of the distinct mutations were found in a single case (80\%), whereas $20 \%$ of the mutations were observed more than once. Two founder mutations, KCNQ1 p.Y111C and KCNQ1 p.R518*, accounted for $25 \%$ of the genotype-positive index cases. Genetic cascade screening of 481 relatives to the 103 index cases with an identified mutation revealed $41 \%$ mutation carriers who were at risk of cardiac events such as syncope or sudden unexpected death.

Conclusion: In this cohort of Swedish index cases with suspected LQTS, a disease-causing mutation was identified in $52 \%$ of the referred patients. Copy number variations explained $2 \%$ of the mutations and 3 of 36 selected cases (8\%) harboured a mutation in the RYR2 gene. The mutation panorama is characterised by founder mutations (25\%), even so, this cohort increases the amount of known LQTS-associated mutations, as approximately one-third (28\%) of the detected mutations were unique.
\end{abstract}

Keywords: Arrhythmia, Long QT syndrome, lon-channel, Founder mutation, Variant of unknown significance

\footnotetext{
* Correspondence: evalena.stattin@medbio.umu.se

${ }^{1}$ Department of Medical Biosciences, Medical and Clinical Genetics, Umeå University, Umeå, Sweden

Full list of author information is available at the end of the article
} 


\section{Background}

Long QT syndrome (LQTS) is an autosomal dominant inherited arrhythmogenic disease and a significant cause of sudden cardiac death (SCD), usually in young and otherwise healthy individuals. LQTS is characterised by delayed ventricular repolarisation, seen as prolongation of the QT-interval on the electrocardiogram (ECG), which predisposes to Torsade-de-Pointes (TdP) and subsequent sudden death by ventricular fibrillation [1,2]. TdP or ventricular tachyarrhythmia is often selfterminating and presents as syncope with loss of consciousness, the most frequent symptom of LQTS. The phenotype is highly variable in expressivity and incomplete in penetrance [3]. Although the majority of LQTS patients show a diagnostic prolongation of the QTinterval on resting ECG, a normal ECG with a normal QTc is not enough to rule out LQTS, since up to approximately $40 \%$ of the patients may present with a normal QT-interval. A LQTS mutation carrier without prolonged QTc has a 10\% risk of major cardiac events by the age of 40 years when left without treatment [4]. Cardiac events are often prompted by physical activity or by intense emotion or stress, but can also occur at rest or during sleep [5,6]. Exercise-induced syncope can also be caused by another inherited ion-channel disease, named catecholaminergic polymorphic ventricular tachycardia (CPVT), which is characterised by cardiac electrical instability exacerbated by acute activation of the adrenergic nervous system [7]. Some patients suspected to have LQTS might actually have CPVT, since there is a clinical overlap between these disorders $[8,9]$.

The prevalence of LQTS has been estimated to 1/ 2,000 in the population [10]. To date, 13 different genes have been associated with LQTS, all encoding subunits of cardiac ion-channels $\left(\mathrm{K}^{+}, \mathrm{Na}^{+}\right.$or $\left.\mathrm{Ca}^{2+}\right)$ or ion-channel regulatory proteins [11]. More than $90 \%$ of the mutations are found in five of the genes (KCNQ1, KCNH2, SCN5A, KCNE1 and KCNE2), and mutation analysis of these five LQTS-causing genes reveals a mutation in about $75 \%$ of patients with a clinical diagnosis of LQTS [8,12-15]. Typically, the disease-causing mutation is a missense mutation that is unique for the family, although founder mutations have been described in different, relatively isolated populations [16-18]. The occurrence of families with compound heterozygote mutations or apparent digenic inheritance, as well as rare variants of uncertain significance (VUS), further complicates the genetics of LQTS $[19,20]$.

First-degree relatives of a mutation carrier are at 50\% risk of carrying the mutation [15], and familial cascade screening should thus be offered immediately to all families with a disease-causing mutation. Identifying additional family members at risk for the condition is of critical importance since they can get preventive treatment, thus decreasing the risk of fatal cardiac events. Here, we examine the spectrum of mutations in 200 unrelated cases referred for LQTS genetic testing in a Swedish population.

\section{Methods \\ Study participants}

Between March 2006 and October 2009, a total of 200 unrelated index cases (138 females; 62 males) were referred to the Department of Clinical Genetics, Umeå University Hospital, Sweden, for LQTS genetic testing as part of ordinary health care. Clinical data, including 12lead ECG, personal history of syncope, treatment with beta-blockers, and family history, was retrospectively collected from referring physicians. The mean age of the 200 index patients at the time of ascertainment was 33 $( \pm 20)$ years. Corrected QT measurements were obtained from 125 index cases by two different investigators (UBD, SJ) who were blinded to genetic status and the identity of the patient. QT interval was obtained from 12-lead ECG and corrected for heart rate using Bazett's formula. Additionally, 12 QTc measurements of index cases were obtained from referring clinicians.

For the interpretation of novel missense variants, clinical data and blood samples from family members (both parents and siblings when available) were collected to look for co-segregation between the sequence variant and the disease in the family. Pedigrees were constructed using Cyrillic 2.1 (Cyrillic Software, Oxfordshire, United Kingdom).

The Regional Ethical Review Board of Umeå University approved this study. Data for continuous variables are presented as mean, standard deviations (SD) and/or range. The Mann-Whitney test was used for comparison of QTc, and parametric tests were used for comparison of normally distributed variables. Statistical analysis was performed using GraphPad Prism 5.0 (GraphPad Software, Inc. USA).

\section{Mutation analysis}

DNA was extracted from peripheral blood lymphocytes using a standard salting-out method. Genomic DNA of the 200 index cases were analysed for mutations in all protein-coding exons and their flanking splice site regions of the genes KCNQ1 (NM_000218.2 and NM_181798.1), KCNH2 (NM_000238.2 and NM_172057.1), SCN5A (NM_198056.1), KCNE1 (NM_000219.2), and KCNE2 (NM_172201.1) using PCR, denaturing high-performance liquid chromatography (DHPLC; WAVE, Transgenomic, Omaha, Neb), and/or bi-directional sequencing on the CEQ 8000 (Beckman Coulter, Fullerton, CA, USA) or the ABI 3100 Genetic Analyzer (Applied Biosystems, Foster City, CA, USA). All primers were checked for absence of SNPs to avoid problems with allelic dropout. All five 
common LQTS genes were analysed regardless of whether a mutation had been identified in one of the genes. Briefly, samples were PCR-amplified by standard methods (primer sequences available on request) and then analysed by DHPLC at one or more temperatures based on the melting profile of the fragment, as determined by Navigator Software version 2.1.0 (Transgenomic). Chromatograms were subjectively grouped, depending on the differences in the profile from normal and known polymorphic variants. Where abnormal patterns of elution were identified, the fragments were sequenced for detection of rare variants. To ensure relevance, all likely pathogenic changes were re-amplified using a different dilution of the same sample.

For cascade screening of relatives, mutation analysis was performed by sequencing as described above, or by directed mutation analysis with MGB probes using the TaqMan 7000 (Applied Biosystems, Foster City, CA, USA). In the latter case, a positive and a genotype- negative familial control was included in each analysis.

All samples were analysed for large deletions or duplications using multiplex ligation-dependent probe amplification (MLPA) with the SALSA P114-A2 kit (MRC-Holland), which covers exons 1B, 1-4, 6-13 and 15-16 for KCNQ1 (NM_000218.2 and NM_181798.1), exons 1B, 1-4, 6, 9-10 and 14 for KCNH2 (NM_000238.2 and NM_172057.1), exons 1-2 for KCNE2 (NM_172201.1), exons 2-4 for KCNE1 (NM_000219.2), and exons 2, 4, 25 and 27 for SCN5A (NM_198056.1). Thirty-six of the LQTS genotype-negative index cases were also analysed for mutations in 23 of the 105 functionally most important exons $(8-15,44-50,83,88-105)$ of the gene RYR2 (NM_001035.2). These cases were selected for RYR2 screening based on a history of sudden unexpected death $(n=1)$, aborted cardiac arrest $(n=10)$, ICD treatment $(n=3)$, documented arrhythmia $(n=3)$, and/or syncope $(n=31)$ and/or a family history of SCD $(n=11)$.

\section{Defining mutation status}

Sequences were evaluated using the software Sequencher $^{\mathrm{Tm}} 4.9$ (Gene Codes Corporation, MI, USA). All identified LQTS-associated mutations and other variants were denoted using nomenclature recommended by Human Genome Variation Society (HGVS) [21]. To be considered as a LQTS-causing mutation, the variant must disrupt or change either the open reading frame (i.e., missense, nonsense, insertion/deletion, or frame shift mutations) or the conserved splice recognition sequences (the first two intronic nucleotides flanking the exon). Variants that did not change the open reading frame (i.e. synonymous) and intronic variants located outside of the splice recognition sequence (i.e. beyond IVS-2 or IVS+2) were not considered unless an effect on splicing could be predicted using bioinformatic tools (SpliceSiteFinder, MaxEntScan, NNSPLICE and GeneSplicer).

In addition, variants that were previously described in healthy individuals and in NCBI dbSNP as common or rare single nucleotide polymorphisms, such as KCNQ1 p.P448R, KCNE1 p.D85N, SCN5A p.H558R, or SCN5A p.A572D, were not considered to be a pathogenic mutation. In silico predictions were made for all putative mutations using the Alamut software version 1.5 (Interactive Biosoftware, Rouen, France). The Alamut software assists in evaluation of missense variants by compiling output from a number of bioinformatic prediction tools, including Polymorphism Phenotyping (PolyPhen), Sorting Intolerant From Tolerant (SIFT) and Align Grantham Variation and Grantham Deviation (Align-GVGD) [22-24].

Novel missense variants were considered mutations only if an effect on the protein could be predicted using bioinformatic tools, and/or if they were absent from 100 control individuals, from the same population, and/or if they co-segregated with affected family members. For all novel missense variants, phylogenetic conservation was evaluated using the Alamut software.

\section{Results}

\section{Subjects and clinical phenotype}

DNA for mutation screening was available from 200 index patients (138 females; 62 male) referred for molecular genetic screening of long QT-syndrome to the Department of Clinical Genetics, Umeå University Hospital, Sweden. Referrals came from all six health care regions, 44 cases from the North health care region, 36 from Uppsala-Örebro, 54 from Stockholm, 43 from the West, 17 from the Southeast, and 6 cases from the South health care region. Questionnaires with clinical data were received for 125 of the index patients from referring physicians. The demographics (age, sex, QTc, symptoms, family history, and treatment with beta-blockers) of all available patients are summarised in Table 1.

The average age at ascertainment was $33 \pm 20$ years (range 13 days to 79 years). An ECG was available for 137 (68\%) of the index cases. The average QTc among all available index patients was $463 \mathrm{~ms}( \pm 44)$. The average QTc was $479 \mathrm{~ms}( \pm 37)$ among KCNQ1 mutation carriers, $472 \mathrm{~ms}( \pm 30)$ among KCNH2 mutation carriers, and $505 \mathrm{~ms}( \pm 66)$ among SCN5A mutation carriers. The average QTc among index cases without an identified mutation was $445 \mathrm{~ms}( \pm 41)$ (Table 1). Although there was no significant difference in QTcinterval between LQT1-3 mutation carriers, there was a significant difference in QTc interval between mutation carriers and index cases without an identified mutation (Figure 1). Among the genotype-positive cases there were 33 individuals with a QTc $\geq 480 \mathrm{~ms}$, and among the 
Table 1 Demographics of all available, unrelated index cases referred for molecular genetic testing regarding Long QT syndrome in ordinary health care

\begin{tabular}{|c|c|c|c|c|c|c|c|c|c|}
\hline & & & & Mutation po & itive & & & & \\
\hline & Total cohort & $\begin{array}{l}\text { KCNQ1 } \\
\text { positive }\end{array}$ & $\begin{array}{l}K C N H 2 \\
\text { positive }\end{array}$ & $\begin{array}{l}\text { SCN5A } \\
\text { positive }\end{array}$ & $\begin{array}{l}\text { KCNE1 } \\
\text { positive }\end{array}$ & $\begin{array}{l}\text { KCNE2 } \\
\text { positive }\end{array}$ & $\begin{array}{l}R Y R 2 \\
\text { positive }\end{array}$ & $\begin{array}{l}\text { LQTS } \\
\text { positive }\end{array}$ & $\begin{array}{l}\text { Genotype } \\
\text { negative }\end{array}$ \\
\hline $\begin{array}{l}\text { Number of index } \\
\text { cases }\end{array}$ & 200 & 60 & 25 & 13 & 1 & 1 & 3 & 100 & 97 \\
\hline $\begin{array}{l}\text { Mean age, SD } \\
\text { range, years }\end{array}$ & $\begin{array}{l}33 \pm 20 \\
0-79\end{array}$ & $\begin{array}{l}36 \pm 23 \\
0-79\end{array}$ & $\begin{array}{l}29 \pm 17 \\
3-69\end{array}$ & $\begin{array}{l}24 \pm 16 \\
0-52\end{array}$ & 49 & 60 & $\begin{array}{l}20 \\
13-32\end{array}$ & $\begin{array}{l}34 \pm 21 \\
0-79\end{array}$ & $\begin{array}{l}32 \pm 20 \\
0-76\end{array}$ \\
\hline Sex, female/male & $138 / 62$ & $45 / 15$ & $19 / 6$ & $6 / 7$ & $1 / 0$ & $1 / 0$ & $1 / 2$ & $73 / 27$ & $65 / 32$ \\
\hline $\begin{array}{l}\text { Average QTc, SD } \\
\text { range, ms }\end{array}$ & $\begin{array}{l}463 \pm 44 \\
305-640(136)\end{array}$ & $\begin{array}{l}479 \pm 37 \\
403-597(41)\end{array}$ & $\begin{array}{l}472 \pm 30 \\
436-565(20)\end{array}$ & $\begin{array}{l}505 \pm 66 \\
434-640(10)\end{array}$ & $447-(1)$ & $478-(1)$ & $\begin{array}{l}428 \\
395-454(3)\end{array}$ & $\begin{array}{l}481 \pm 41 \\
403-640(73)\end{array}$ & $\begin{array}{l}445 \pm 41 \\
305-510(60)\end{array}$ \\
\hline $\begin{array}{l}\text { Syncope, \% } \\
\text { Yes/No }\end{array}$ & $\begin{array}{l}61 \% 72 / 46 \\
(118)\end{array}$ & $\begin{array}{l}53 \% 19 / 17 \\
(36)\end{array}$ & $\begin{array}{l}68 \% 13 / 6 \\
(19)\end{array}$ & $4 / 4(8)$ & No (1) & No (1) & $1 / 1(2)$ & $\begin{array}{l}55 \% 36 / 29 \\
(65)\end{array}$ & $\begin{array}{l}69 \% 35 / 16 \\
(51)\end{array}$ \\
\hline $\begin{array}{l}\text { Family history, \% } \\
\text { Yes/No }\end{array}$ & $\begin{array}{l}43 \% 49 / 65 \\
(114)\end{array}$ & $\begin{array}{l}76 \% 29 / 9 \\
(38)\end{array}$ & $\begin{array}{l}63 \% 12 / 7 \\
(19)\end{array}$ & $3 / 3(6)$ & Yes (1) & No (1) & $1 / 1(2)$ & $\begin{array}{l}69 \% 45 / 20 \\
(65)\end{array}$ & $\begin{array}{l}6 \% 3 / 44 \\
(47)\end{array}$ \\
\hline $\begin{array}{l}\text { B-blockers, \% } \\
\text { Yes/No }\end{array}$ & $\begin{array}{l}52 \% 59 / 54 \\
(113)\end{array}$ & $\begin{array}{l}67 \% 22 / 11 \\
(33)\end{array}$ & $\begin{array}{l}68 \% 13 / 6 \\
(19)\end{array}$ & $3 / 8(8)$ & Yes (1) & Yes (1) & $2 / 0(2)$ & $\begin{array}{l}65 \% 40 / 22 \\
(62)\end{array}$ & $\begin{array}{l}35 \% 17 / 32 \\
(49)\end{array}$ \\
\hline
\end{tabular}

The numbers in parenthesis refers to the number of cases in each category. No percentages are calculated if there are less than 10 cases.

genotype-negative cases, 12 had QTc $\geq 480 \mathrm{~ms}$. Among the patients with a prolonged QT interval, 77\% carried a LQTS mutation whereas $23 \%$ had no mutation. Furthermore, 38\% of the patients with a normal QT interval carried a mutation, whereas $62 \%$ had no mutation. Among subjects selected for RYR2 screening $(\mathrm{n}=36)$ the average QTc was $432 \mathrm{~ms}$ (range 347-477 ms), of which five of them had a QTc prolongation $>460 \mathrm{~ms}$ (25 available ECG).

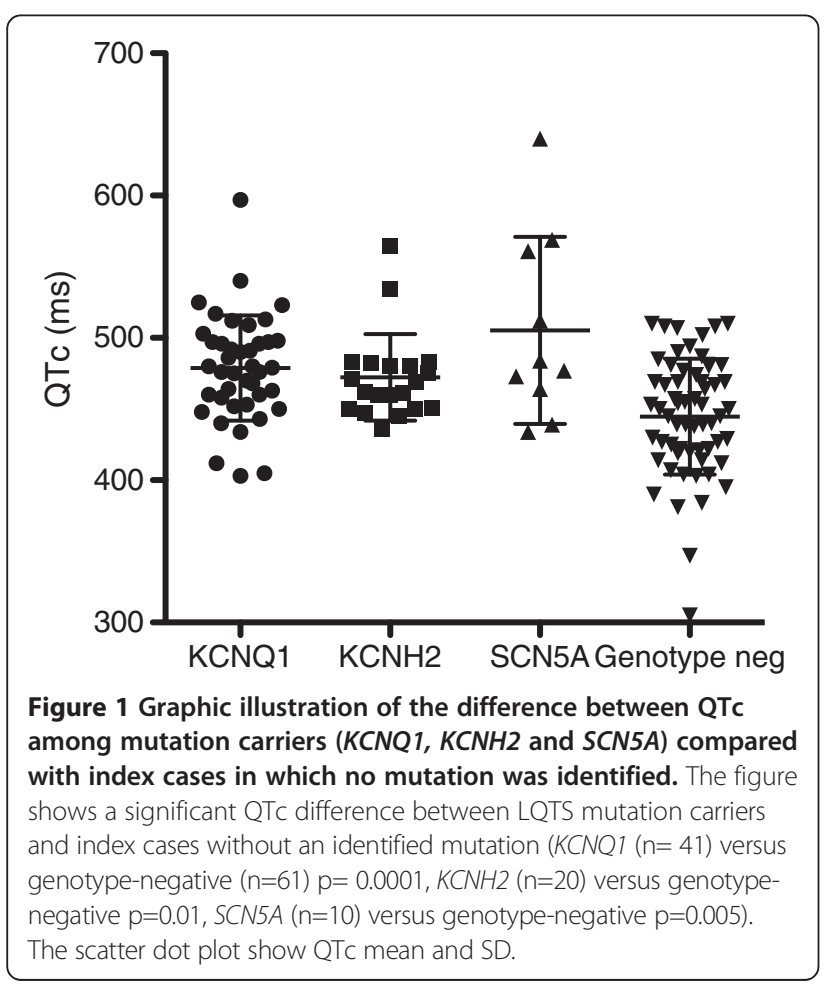

\section{Molecular genetic analysis}

In total, a mutation was identified in 103 of the 200 (52\%) index patients (Table 2).

Sequence analysis of the LQTS-associated genes revealed a pathogenic mutation in 98 of the 200 index patients. Furthermore, the MLPA analysis revealed 2 different CNVs in $K C N H 2$ (exon 2 dup, and exon 9-10 del) in two patients, and the $R Y R 2$ screening revealed a pathogenic mutation in 3 of the 36 selected patients (8\%). Mutations in the KCNQ1 gene were most prevalent (58\%), followed by KCNH2 (24\%), SCN5A (13\%), RYR2 (3\%), KCNE1 (1\%) and KCNE2 (1\%). Among the 103 mutationpositive patients, 99 had a single heterozygous mutation, whereas four female patients (4\%) carried multiple mutations (KCNQ1 c.1893dup; QTc 512 ms, KCNE1 p.R32H; QTc 447 ms, KCNQ1 p.P73T, SCN5A p.V411M; QTc 464 ms and KCNQ1 p.Y111C, SCN5A p.A29V; QTc 490ms); two homozygous and two compound heterozygous mutation carriers (Table 2). None of the patients hosting double mutations displayed the phenotype of Jervell and Lange-Nielsen syndrome with clinical deafness, even though the mutations resided on different alleles.

The 103 genotype-positive patients stemmed from 64 distinct mutations, the majority of which were observed in a single case $(n=51)$. Of the 13 mutations that were observed more than once, the six most common were KCNQ1 p.Y111C (n=20), KCNQ1 p.R518* $(\mathrm{n}=6), S C N 5 A$ p.V411M (n=4), SCN5A c.4519_4527del (n=4), KCNQ1 p.Q530* $(\mathrm{n}=3)$, and KCNQ1 c.572_576del $(\mathrm{n}=3)$.

Approximately one-third (28\%) of the mutations had never previously been reported in LQTS at the time of detection, and were thus novel to this Swedish cohort. These include seven mutations in KCNQ1, nine in $K C N H 2$ and two in SCN5A (Table 2). None of these mutations were observed in 100 analysed population-matched control 
Table 2 Pathogenic mutations in the KCNQ1, KCNE1, KCNH2, KCNE2, SCN5A and RYR2-genes among Swedish index cases referred for genetic testing with respect to LQTS

\begin{tabular}{|c|c|c|c|c|c|c|c|}
\hline Gene & Exon & Nucleotide change & Amino acid change & Mutation type & Region & No. of probands & Reference \\
\hline \multirow[t]{30}{*}{ KCNQ1 } & 1 & c. $217 C>A$ & p.P73T & Missense & N-term & $1^{\mathrm{b}}$ & Kapplinger et al. 2009 \\
\hline & 1 & c. $332 A>G$ & p.Y111C & Missense & $\mathrm{N}$-term & $20^{\mathrm{b}}$ & Splawski et al. 2000 \\
\hline & 3 & c. $506 C>G$ & p.T169R & Missense & S2 & $1^{c}$ & This study ${ }^{a}$ \\
\hline & 3 & C. $509 A>G$ & p.E170G & Missense & S2-S3 & 1 & This study ${ }^{a}$ \\
\hline & 3 & c.572_576del & p.R192Cfs91* & Frame shift & S2-S3 & 3 & Tyson et al. 1997 \\
\hline & 4 & $c .643 G>A$ & p.V215M & Missense & S3 & 1 & Napolitano et al. 2005 \\
\hline & 4 & c. $674 \mathrm{C}>\mathrm{T}$ & p.S225L & Missense & S4 & 2 & Priori et al 1999 \\
\hline & 5 & c. $727 C>T$ & p.R243C & Missense & S4-S5 & 2 & Franqueza et al.1999 \\
\hline & 5 & c.734G $>\mathrm{T}$ & p.G245V & Missense & S4-S5 & 1 & This study ${ }^{a}$ \\
\hline & 7 & $c .935 C>T$ & p.T3121 & Missense & Pore & 1 & Wang et al. 1996 \\
\hline & 7 & c. $944 A>G$ & p.Y315C & Missense & Pore & 1 & Splawski et al. 1998 \\
\hline & 7 & $c .973 G>T$ & p.G325W & Missense & S6 & 1 & This study ${ }^{a}$ \\
\hline & 7 & c. $973 \mathrm{G}>\mathrm{A}$ & p.G325R & Missense & S6 & 2 & Tanaka et al. 1997 \\
\hline & 7 & c.1023_1024delinsTT & p.L342F & Missense & S6 & 1 & Donger et al. 1997 \\
\hline & 7 & C. $1031 C>A$ & p.A344E & Missense & S6 & 1 & Tester et al. 2005 \\
\hline & 8 & c.1033-1G>C & splice & Splice site & S6 & 1 & This study ${ }^{a}$ \\
\hline & 8 & c. $1046 C>G$ & p.S349W & Missense & C-term & 1 & Splawski et al. 2000 \\
\hline & 8 & c.1066_1071del & p.Q356_Q357del & Deletion & C-term & 1 & Liang et al. 2003 \\
\hline & 10 & c.1265delA & p.K422Sfs*10 & Frame shift & C-term & 1 & Kapplinger et al. 2009 \\
\hline & 12 & c. $1552 C>T$ & p.R518* & Nonsense & C-term & 6 & Wei et al. 2000 \\
\hline & 12 & C. $1588 \mathrm{C}>\mathrm{T}$ & p.Q530* & Nonsense & C-term & 3 & Tranebjærg et al. 1999 \\
\hline & 13 & C. $1615 C>T$ & p.R539W & Missense & C-term & 1 & Chouabe et al.1997 \\
\hline & 13 & c. $1664 \mathrm{G}>\mathrm{A}$ & p.R555H & Missense & C-term & 1 & Lupoglazoff et al. 2004 \\
\hline & 14 & c.1697C >T & p.S566F & Missense & C-term & 1 & Splawski et al. 2000 \\
\hline & 15 & c. $1766 \mathrm{G}>\mathrm{A}$ & p.G589D & Missense & SAR & 1 & Piippo et al. 2001 \\
\hline & 15 & c. $1772 \mathrm{G}>\mathrm{A}$ & p.R591H & Missense & SAR & 1 & Neyroud et al. 1999 \\
\hline & 15 & c. $1780 C>T$ & p.R594* & Nonsense & SAR & 1 & This study ${ }^{a}$ \\
\hline & 15 & c. $1781 \mathrm{G}>\mathrm{A}$ & p.R594Q & Missense & SAR & 1 & Splawski et al. 2000 \\
\hline & 16 & c. $1801 C>T$ & p.Q601* & Nonsense & SAR & 1 & This study ${ }^{a}$ \\
\hline & 16 & c.1893dup & p.R632Qfs*20 & Frame shift & C-term & $1^{b}$ & Neyroud et al. 1999 \\
\hline \multirow[t]{13}{*}{ KCNH2 } & 2 & exon 2 duplication & & Duplication & $\mathrm{N}$-term & 1 & This study ${ }^{a}$ \\
\hline & 2 & c. $128 \mathrm{~A}>\mathrm{G}$ & p.Y43C & Missense & PAS & 1 & Napolitano et al. 2005 \\
\hline & 2 & c. $157 \mathrm{G}>\mathrm{A}$ & p.G53S & Missense & PAS & 1 & Nagaoka et al. 2008 \\
\hline & 2 & c. $182 A>G$ & p.Q61R & Missense & PAS & $1^{c}$ & This study ${ }^{a}$ \\
\hline & 2 & c.235_242del & p.A79Dfs*63 & Frame shift & $\mathrm{N}$-term & 1 & This study ${ }^{a}$ \\
\hline & 2 & c.244_252dup & p.182_Q84dup & Insertion & PAC & 1 & Larsen et al. 2001 \\
\hline & 2 & c. $284 A>G$ & p.E95G & Missense & PAC & $1^{c}$ & This study ${ }^{a}$ \\
\hline & 3 & c.453delC & p.T152Pfs*14 & Frame shift & $\mathrm{N}$-term & 2 & Swan et al. 1999 \\
\hline & 4 & $c .526 C>T$ & p.R176W & Missense & $\mathrm{N}$-term & 1 & Swan et al. 1999 \\
\hline & 4 & c.853_859dup & p.D287Gfs*47 & Frame shift & $\mathrm{N}$-term & 1 & This study ${ }^{a}$ \\
\hline & 5 & C. $982 C>T$ & p.R328C & Missense & $\mathrm{N}$-term & 1 & Tester et al. 2005 \\
\hline & 5 & c. $1094 \mathrm{~A}>\mathrm{G}$ & p.E365G & Missense & $\mathrm{N}$-term & 1 & This study ${ }^{a}$ \\
\hline & 7 & C. $1655 T>C$ & p.L552S & Missense & S5 & 2 & Swan et al. 1999 \\
\hline
\end{tabular}




\begin{tabular}{|c|c|c|c|c|c|c|c|}
\hline & 7 & c. $1688 \mathrm{G}>\mathrm{A}$ & p.W563* & Nonsense & S5 & 1 & Berge et al. 2005 \\
\hline & 7 & c. $1706 \mathrm{~A}>\mathrm{G}$ & p.Y569C & Missense & S5 & 1 & This study ${ }^{a}$ \\
\hline & 7 & c. $1750 \mathrm{G}>\mathrm{A}$ & p.G584S & Missense & S5 & 1 & Swan et al. 1999 \\
\hline & 9 & $c .2254 C>T$ & p.R752W & Missense & cNBD & 1 & Splawski et al. 2000 \\
\hline & 9 & c. $2312 A>G$ & p.H771R & Missense & cNBD & 1 & This study ${ }^{a}$ \\
\hline & 10 & c. $2453 C>T$ & p.S818L & Missense & cNBD & 1 & Berthet et al. 1999 \\
\hline & $9-10$ & exon 9-10 deletion & & Deletion & cNBD/C-term & 1 & This study ${ }^{a}$ \\
\hline & 12 & c.2959_2960del & p.L987Vfs*131 & Frame shift & C-term & 2 & Splawski et al. 2000 \\
\hline & 13 & c.3107dupG & p.D1037Rfs*82 & Frame shift & C-term & 1 & Berthet et al. 1999 \\
\hline \multirow[t]{8}{*}{ SCN5A } & 2 & $c .86 \mathrm{C}>\mathrm{T}$ & p.A29V & Missense & $\mathrm{N}$-term & $1^{\mathrm{b}}$ & This study ${ }^{a}$ \\
\hline & 7 & c. $715 A>G$ & p. $1239 \mathrm{~V}$ & Missense & DI-S4/S5 & 1 & Fodstad et al. 2004 \\
\hline & 10 & c. $1231 \mathrm{G}>\mathrm{A}$ & p.V411M & Missense & DI-S6 & $4^{\mathrm{bc}}$ & Tester et al. 2005 \\
\hline & 22 & c.3893C>T & p.P1298L & Missense & DIII-S4 & 1 & This study ${ }^{a}$ \\
\hline & 23 & $c .4000 A>G$ & p.11334V & Missense & DIII-S4/S5 & 1 & Kapplinger et al. 2009 \\
\hline & 26 & c.4519_4527del & p.Q1507_P1509del & Deletion & DIII-DIV & 4 & Keller et al. 2003 \\
\hline & 28 & c. $4877 \mathrm{G}>\mathrm{C}$ & p.R1626P & Missense & DIV-S4 & 1 & Napolitano et al. 2005 \\
\hline & 28 & c.5350G >A & p.E1784K & Missense & C-term & 1 & Wei et al. 1999 \\
\hline KCNE1 & 4 & c. $95 \mathrm{G}>\mathrm{A}$ & p.R32H & Missense & Extracellular & $1^{\mathrm{b}}$ & Splawski et al. 2000 \\
\hline KCNE2 & 2 & C.170T>C & p.157T & Missense & Transmembrane & 1 & Abbott et al. 1999 \\
\hline \multirow[t]{2}{*}{ RYR2 } & 44 & c. $6737 C>T$ & p.S2246L & Missense & Cytoplasmatic loop & $2^{c}$ & Priori et al. 2001 \\
\hline & 101 & C. $14553 C>A$ & p.F4851L & Missense & TM domain & 1 & Hayashi et al. 2009 \\
\hline
\end{tabular}

a Denotes a novel variant, unique to this cohort. ${ }^{b}$ Compound heterozygous or homozygous mutations ${ }^{c}$ de novo mutation.

individuals. Furthermore, with the exception of SCN5A p.P1298L, none were present in any of the large whole exome sequencing projects "1000 genomes project" or "NHBLI exome sequencing project (ESP)". The putative mutation SCN5A p.P1298L was referred to as rs28937319 in dbSNP with unknown allele frequency and status probable-pathogenic. Although it has been associated with sick sinus syndrome [25], it has never been reported previously in LQTS patients, and is thus considered a novel LQTS mutation.

Evaluation of the pathogenicity in seven of the novel mutations was straightforward, including two stop mutations (KCNQ1 p.R594*, and KCNQ1 p.Q601*), two frameshift mutations resulting in premature stops $(\mathrm{KCNH} 2$ p.A79Dfs"63, and $K C N H 2$ p.D287Gfs"47), two CNVs in $\mathrm{KCNH} 2$ as described above, and one splice mutation in position IVS-1 (KCNQ1 c.1033-1G>C). For the eleven novel missense variants, the most important factor in determining the pathogenicity was the degree to which a missense change was conserved in orthologs and in other proteins with the same domain (Table 3). Phylogenetic alignments for the novel missense mutations are presented in Additional file 1, showing that the mutations affected highly conserved residues. In silico data and cosegregation are summarised in Table 3. In silico analysis using SIFT predicted that none of the variants seen would be tolerated, which is consistent with them being pathogenic [22]. PolyPhen conservation scores predicted seven of the variants to be probably damaging and four to be possibly damaging (Table 3) [23]. In addition, cosegregation analyses of the novel missense variants were performed in all families where samples from relatives were available. The pedigrees showed perfect co-segregation between the novel sequence variant and the disease in six families, whereas in four families no interpretation was possible due to non-penetrant or borderline QTc, and in five other families there was no samples available or missing data (data not shown). In the remaining three families, the variant had occurred de novo.

Among the 64 distinct mutations, missense mutations were most common (70\%), followed by frame-shift mutations (12.5\%), nonsense mutations $(8 \%)$, in-frame deletions/insertions (5\%), large deletions/insertions (3\%), and splice-site mutations (1.5\%) (Table 4). Most of the 64 distinct mutations $(47 \%)$ were localised to the transmembrane spanning and pore-forming domains, whereas $25 \%$ were localised to the $\mathrm{N}$-terminus, and $28 \%$ to the $\mathrm{C}$-terminus.

In 97 of the 200 index patients, no pathogenic mutation was identified. In 19 of these patients rare missense variants were detected, that could potentially contribute 
Table 3 Characteristics of the novel missense mutations unique to the Swedish cohort

\begin{tabular}{|c|c|c|c|c|c|c|c|c|c|}
\hline Gene & Exon & $\begin{array}{l}\text { Nucleotide } \\
\text { change }\end{array}$ & $\begin{array}{l}\text { Amino acid } \\
\text { change }\end{array}$ & Region & GD & SIFT & PolyPhen & Align-GVGD & $\begin{array}{l}\text { Segregation } \\
\text { analysis }\end{array}$ \\
\hline \multirow[t]{4}{*}{ KCNQ1 } & 3 & c. $506 C>G$ & p.T169R & S2 & 71 & not tolerated & Possibly damaging & $\mathrm{CO}$ & de novo \\
\hline & 3 & c. $509 \mathrm{~A}>\mathrm{G}$ & p.E170G & S2-S3 & 98 & not tolerated & Probably damaging & CO & Yes \\
\hline & 5 & c.734G >T & p.G245V & S4-S5 & 109 & not tolerated & Probably damaging & $\mathrm{CO}$ & Borderline \\
\hline & 7 & $c .973 \mathrm{G}>\mathrm{T}$ & p.G325W & S6 & 184 & not tolerated & Probably damaging & C65 & Yes \\
\hline \multirow[t]{5}{*}{ KCNH2 } & 2 & c. $182 A>G$ & p.Q61R & PAS & 43 & not tolerated & Possibly damaging & $\mathrm{CO}$ & de novo \\
\hline & 2 & c. $284 A>G$ & p.E95G & PAC & 98 & not tolerated & Probably damaging & CO & de novo \\
\hline & 5 & c.1094A>G & p.E365G & $\mathrm{N}$-term & 98 & not tolerated & Possibly damaging & CO & Yes \\
\hline & 7 & c. $1706 \mathrm{~A}>\mathrm{G}$ & p.Y569C & S5 & 194 & not tolerated & Probably damaging & C65 & Borderline \\
\hline & 9 & $c .2312 A>G$ & p.H771R & CNBD & 29 & not tolerated & Probably damaging & $\mathrm{C} 25$ & N/A \\
\hline \multirow[t]{2}{*}{ SCN5A } & 2 & $c .86 C>T$ & p.A29V & N-term & 65 & not tolerated & Probably damaging & C65 & Yes \\
\hline & 22 & c. $3893 C>T$ & p.P1298L & DIII-S4 & 98 & not tolerated & Possibly damaging & C65 & N/A \\
\hline
\end{tabular}

$\mathrm{GD}$, Grantham distance ordered from largest difference $(\mathrm{GD}=215)$ between the substituted amino acids to no difference (GD=0); $\mathrm{SIFT}$, sorting intolerant from tolerant; PolyPhen, Polymorphism Phenotyping predicting variants as probably damaging, possibly damaging or benign; Align-GVGD, Align Grantham variation and Grantham distance ordered from most likely (C65) to interfere with function to least likely (C0); Segregation analysis: Yes, segregation demonstrated; de novo, mutation not present in either parent; Borderline, non-penetrant or borderline QTc; N/A, samples not available or missing data.

to the disease phenotype, but these were not considered to be pathogenic by themselves. Additional file 2 describes all identified rare variants in the Swedish cohort with a frequency less than $5 \%$, as well as all missense substitutions, all of which were classified as normal genetic variants.

\section{Genetic cascade screening in family members}

In the 103 unrelated families where a LQTS or CPVT disease-causing mutation was identified, a total of 481 relatives have undergone cascade genetic testing. Of these relatives, 199 (41\%) were mutation carriers, while 282 (59\%) did not carry a mutation. The mean number

Table 4 Summary of population screening studies of long QT syndrome

\begin{tabular}{|c|c|c|c|c|c|c|c|}
\hline & & $\begin{array}{l}\text { Splawski } \\
\text { et al. } 2000\end{array}$ & $\begin{array}{l}\text { Tester et al. } 2005 \\
\text { Tester et al. } 2005^{a}\end{array}$ & $\begin{array}{l}\text { Napolitano } \\
\text { et al. } 2005\end{array}$ & $\begin{array}{l}\text { Berge } \\
\text { et al. } 2008\end{array}$ & $\begin{array}{l}\text { Kapplinger } \\
\text { et al. } 2009\end{array}$ & $\begin{array}{l}\text { This } \\
\text { study }\end{array}$ \\
\hline Number of unrelated index cases (n) & & 262 & 541 & 430 & 169 & 2500 & 200 \\
\hline $\begin{array}{l}\text { Detection rate (\%) All cases/more } \\
\text { stringent criteria ( }{ }^{*} \text { Schwartz score } \geq 4 \text { ) }\end{array}$ & & 51 & $50 / 72^{*}$ & 72 & $32 / 71$ & 36 & 52 \\
\hline Novel mutations (\%) & & 60 & 59 & 59 & 54 & 60 & 28 \\
\hline Multiple mutations (\%) & & - & 10 & 5 & 0 & 9 & 4 \\
\hline \multirow[t]{7}{*}{ Mutated gene: } & KCNQ1 (\%) & 39 & 42 & 49 & 43 & 43 & 58 \\
\hline & KCNH2 (\%) & 51 & 42 & 39 & 46 & 32 & 24 \\
\hline & SCN5A (\%) & 6 & 15 & 10 & 9 & 13 & 13 \\
\hline & KCNE1 (\%) & 2 & 0.5 & 2 & 2 & 3 & 1 \\
\hline & KCNE2 (\%) & 2 & 0.5 & 1 & - & 1 & 1 \\
\hline & RYR2 (\%) & - & \multirow{2}{*}{$-{ }^{-}{ }^{\mathrm{a}}$} & \multirow[t]{2}{*}{-} & \multirow{2}{*}{-} & \multirow[t]{2}{*}{ - } & \multirow{2}{*}{$\begin{array}{l}3 \\
36 / 8\end{array}$} \\
\hline & RYR2 (n/\%) & & & & & & \\
\hline \multirow[t]{6}{*}{ Mutation type: } & Missense (\%) & 72 & 73 & 72 & 65 & 70 & 70 \\
\hline & Nonsense (\%) & 6 & 6 & 5 & 14 & 6 & 8 \\
\hline & In-frame ins/del (\%) & 5 & 2 & 14 & 3 & 3 & 5 \\
\hline & Frame shift (\%) & 10 & 12 & 6 & 13 & 15 & 12.5 \\
\hline & Splice site (\%) & 7 & 6 & 3 & 5 & 6 & 1.5 \\
\hline & Large ins/del (\%) & - & - & - & - & - & 3 \\
\hline \multirow[t]{3}{*}{ Mutation region: } & N-terminal (\%) & 22 & 16 & 8 & 22 & 8 & 25 \\
\hline & Transmembrane (\%) & 54 & 49 & 64 & 54 & 57 & 47 \\
\hline & C-terminal (\%) & 24 & 35 & 28 & 24 & 35 & 28 \\
\hline
\end{tabular}


of tested individuals in each family was 5.7 (the proband included). In total, 5 of the 105 (5\%) identified mutations had occurred de novo in the index patient (four LQTS mutations and one CPVT mutation, KCNQ1 p.T169R, KCNH2 p.E95G, KCNH2 p.Q61R, SCN5A p.V411M, and RYR2 p.S2246L, see Table 2). However, since both parents were not tested in all families, it is possible that this number is higher (data not shown). In one of the families with a de novo mutation (SCN5A p.V411M), two children but none of the parents were carriers, indicating possible germ-line mosaicism.

\section{Discussion}

In this study, we have determined the mutation panorama in a Swedish cohort referred for genetic LQTS testing as part of ordinary health care. Between March 2006 and October 2009, the department of Clinical Genetics in Umeå was to our knowledge the only laboratory in Sweden screening the LQTS genes. Among the 200 index patients, 64 different mutations were identified in 103 patients (52\%); of which $58 \%$ occurred in KCNQ1, $24 \%$ in $K C N H 2,13 \%$ in $S C N 5 A, 3 \%$ in $R Y R 2,1 \%$ in $K C N E 1$, and $1 \%$ in KCNE2. Thirteen of the mutations were found in more than one family, whereas 51 occurred only once. Among these mutations, 28\% were novel at the time of detection, and had thus never been reported previously.

\section{LQTS founder mutations}

Two of the recurring mutations, KCNQ1 p.Y111C and KCNQ1 p.R518*, were identified in 26 of the 103 cases, thus accounting for approximately $25 \%$ of the mutations in the Swedish LQTS population. We have recently shown that family members carrying these mutations share a common haplotype that is specific for each mutation [26] [Abstract number 154:Winbo A. Stattin E.L. Nordin C. Persson J. Diamant U.B. Jensen S.M. Rydberg A. Origin, genotype and clinical phenotype of the Long QT Syndrome R518X/KCNQ1 mutation in Sweden. Presented at the 46th Annual Meeting of the Association for European Paediatric and Congenital Cardiology (AEPC), May 23-26 2012 in Istanbul]. The mutation KCNQ1 p.Y111C was introduced and enriched in the Ångerman River valley approximately 600 years ago [26]. Functional in-vitro studies have demonstrated that it is a "malignant" mutation with a strong dominantnegative effect, causing disturbed function of the wildtype ion channel $[27,28]$. In contrast to these findings, we recently showed that the KCNQ1 p.Y111C mutation presents with a low incidence of life threatening events in a Swedish Y111C-positive LQTS population [29]. Furthermore, we showed that p.Y111C is a founder mutation in this population [26], a finding which also contrasts to in vitro-data indicating it to be a malignant mutation. One explanation for these discrepancies could be the presence of population-specific modifiers, genetic or other, such as the recently described polymorphisms in the 3'-UTR of KCNQ1, mitigating the effect of the mutated allele by reduced expression [30]. Possibly, one or several of these polymorphisms could exert its attenuating effect through the creation of a novel miRNAbinding site, a theory that has been proposed for other disorders where large differences in phenotypic expression occur [31].

The mutation KCNQ1 p.R518* has previously been reported in several populations [32,33], as well as a founder mutation in Sweden [34] and Norway [16], although Berge et al. did not report any founder mutations in the more recent Norwegian LQTS population survey [8]. A strong founder effect has been described in the Finnish population [17]. In our study, we identified three of the Finnish founder mutations (KCNQ1 p.G589D, KCNH2 p.R176W, and KCNH2 p.L552S), as well as the two common Norwegian mutations (KCNQ1 p.R518* mentioned above, and KCNQ1 p.Q530*) in several of the patients $[16,35]$.

\section{LQTS genotype-negative index cases}

According to published studies, approximately 25\% of index cases with the clinical phenotype of LQTS remain genotype-negative after comprehensive assessment of the three most common LQTS genes (KCNQ1, KCNH2, and $S C N 5 A)[12,13,15]$. In this study, 102 index patients (51\%) referred for LQTS testing were negative after sequencing of the KCNQ1, KCNH2, KCNE1, KCNE2 and $S C N 5 A$ genes. As in any molecular genetic study of disease, there is a possibility that these individuals have mutations missed due to technical limitations (e.g. DHPLC), or located in regions not included in the analysis; such as in the gene promotors or introns of the genes chosen for study, or in another LQTS-associated gene. However, these patients had a significantly shorter QTc, and reported family history than the mutation carriers, and some of them might therefore be suspected of not having LQTS (Figure 1, Table 1). Several publications indicate that patients suspected of having LQTS may actually have CPVT, $[8,9,36]$ and that can be confirmed also in the present study. Among 36 genotypenegative index patients selected for RYR2 screening based on a history of arrhythmia, aborted cardiac arrest and/or syncope and/or a family history of SCD, we identified a disease-causing mutation in $8 \%$. Tester et al. evaluated the prevalence of RYR2 mutations in a cohort of patients referred for screening of LQTS genes, identifying mutations in RYR2 among 6\% of the 269 genotypenegative patients [9]. Berge et al. identified mutations in $R Y R 2$ in $17 \%$ of the 41 genotype-negative index patients referred for LQTS testing [8]. Thus, it is critical to 
recognise CPVT as an important differential diagnosis to LQTS, and to consider mutation screening of the RYR2 gene in patients who do not have a mutation in one of the LQTS-associated genes.

The presence of copy number variants (CNVs) within the LQTS disease genes have also been suggested as an explanation for the lack of identified mutations [37-39]. Therefore, we performed MLPA analysis of all 200 index patients, identifying $2 \mathrm{CNVs}$ in the $\mathrm{KCNH} 2$ gene. Thus, the yield of CNVs was $2.0 \%$ among the 100 genotypenegative index patients without an identified mutation in any of the LQTS genes or RYR2. In the study of Tester et al. CNVs were found in $4.8 \%$ of 42 patients with QTc duration $\geq 480 \mathrm{~ms}$ and/or a Schwartz score $\geq 4$ who were negative for mutations in 12 of the LQTSassociated genes [40]. Eddy et al. identified CNVs in $11.5 \%$ of 26 patients with Schwartz score $\geq 4$ who were negative for mutations in the KCNQ1, KCNH2, and SCN5A genes [38]. Barc et al. identified CNVs in 3.2\% of 93 patients with Schwartz score $\geq 3$ who were negative for mutations in the KCNQ1, KCNH2, and SCN5A genes [39]. These findings suggest that CNVs might be a more frequent cause of LQTS than mutations in all of the less common LQTS-associated genes (ANKB, KCNE1, KCNE2, KCNJ2, CACNA1C, CAV3, SCN4B, AKAP9, and SNTA1) together [38-40]. Thus, it is important to consider MLPA analysis in patients who do not possess a mutation in one of the most common LQTS-associated genes.

\section{Genetic cascade screening in family members}

A total of 481 relatives in the 103 families with an identified mutation have participated in genetic cascade screening, of which $41 \%$ were found to be mutation carriers, and 59\% were not carriers. Thus, 2.9 (302/103) individuals per family carried a mutation and were thereby at risk for LQTS-associated symptoms and SCD. This finding is lower than the result in Norway, where, $4.7(305 / 66)$ patients per family carried a heterozygote mutation [8]. In contrast to Imboden et al. [41] no female predominance among mutation carriers and no non-random inheritance, with a significant greater number of affected than expected, could be observed in this cohort.

\section{This study compared with other population surveys}

In the five largest LQTS population surveys that have been published to date, involving the five most common LQTS-causing genes (KCNQ1, KCNH2, SCN5A, KCNE1 and $K C N E 2$ ), the mutation yield was $72 \%, 51 \%, 50 \%$, $36 \%$, and $32 \%$, respectively (Table 4 ) [8,12-15]. In two of the studies, when using more stringent criteria (i.e. Schwartz score $\geq 4$ ), the mutation detection rate was raised from $50 \%$ to $72 \%$, and from $32 \%$ to $71 \%$, respectively $[8,13]$. In this study, we obtained a mutation detection rate of $52 \%$, which lies in the range of the other population studies. Among individuals with a definite prolonged QTc, 77\% carried a mutation, which is in line with the two studies using more stringent criteria. We were not able to categorise all the index patients, since phenotypic information was not available for all of the patients.

The largest survey, including 2,500 consecutive, unrelated LQTS patients, presented one of the lowest mutation yields of $36 \%$. However, the degree of diagnostic relevance in the referred patients of that study could not be evaluated, also due to lack of phenotypic information.

The mutations in the KCNQ1, KCNH2 and SCN5A genes were distributed over the entire coding regions and adjacent splice sites. The vast majority were heterozygous missense mutations. The distribution of mutations between the different genes and the type of mutation concur with findings of the other population surveys. However, the rate of KCNQ1 mutations is higher in our study (58\%), since both of the Swedish founder mutations p.Y111C and p.R518* are located in this gene. Most of the mutations $(\approx 60 \%)$ in the published surveys have not been reported previously, whereas we only identified $28 \%$ novel mutations in this study. It is possible that this lower yield is due to the more than 10 years of publications of several large LQTS studies, which suggests that the increase in new LQTS mutations is beginning to be saturated.

\section{Probands carrying multiple mutations}

Patients carrying multiple mutations have been shown to present with a more severe phenotype compared to patients carrying only one mutation [19]. In one study, the compound mutation carriers had longer QTc intervals and a younger age-at-onset compared to patients with only one mutation [19]. In this study, four of the 103 (4\%) genotype-positive patients carried more than one definitely pathogenic mutation. Two of them were homozygous for the mutation and two compound heterozygote. All of them are female and have a family history of LQTS. The (homozygous) carrier of the KCNQ1 c.1893dup mutation, had a QTc prolongation of $512 \mathrm{~ms}$; however, there is no information about any history of syncope or current treatment with beta-blockers. The parents of the c.1893dup mutation carrier both carried the mutation in heterozygous form; the mother had a QTc of 435 ms while the father has a QTc denoted as normal (data not shown). The KCNE1 p.R32H (homozygous) mutation carrier, had a QTc of $447 \mathrm{~ms}$, is being treated with beta-blockers and has not experienced syncope. The parents of the p. $\mathrm{R} 32 \mathrm{H}$ mutation carrier were not available for testing, but hemizygosity of the mutation in the proband was excluded by MLPA (data not 
shown). The carrier of the (compound heterozygote) mutations KCNQ1 p.P73T and SCN5A p.V411M, had a history of suspected seizures and syncope, and she was not treated with beta-blockers but with Phenytoin. The carrier of the (compound heterozygote) mutations KCNQ1 p.Y111C and SCN5A p.A29V, had a history of presyncope and a QTc of $490 \mathrm{~ms}$.

In the Norwegian survey, no patients had more than one definitely pathogenic mutation, whereas Kapplinger et al. reported 9\%, and Tester et al. reported 11\% patients with multiple mutations among the genotypepositive patients $[8,13,14]$. In the study of Westenskow et al. compound mutations were reported in $12 \%$ of the genotype-positive LQTS probands. However, of the 20 probands in their study assigned as having multiple mutations, over half possessed either the KCNE1 p.D85N or KCNQ1 p.P448R common polymorphism as the "second hit" [42]. Similarly, Tester et al. reported SCN5A p.A572D as a mutation in 3 of their patients [13]. In our study, SCN5A p.A572D was identified in 3 patients, KCNQ1 p.P448R in 3 patients, and KCNE1 p.D85N in 12 patients, all of which were determined to be non-pathogenic (Additional file 2). In four of the patients, these variants occurred together with a definitely pathogenic mutation. If we had regarded these as pathogenic mutations, our yield of multiple mutations among the genotype-positive patients would have been $8 \%(8 / 103)$ instead of $4 \%$.

\section{Sequence variants of unknown significance - polymorphisms}

Missense mutations are the most frequent form of mutation in the LQTS genes, accounting for about $65-73 \%$ of the mutations in the large LQTS population surveys. Careful interpretation of identified genetic variants is important, because a missense variant may or may not cause an altered/distorted protein and a disease phenotype [43]. In this study, several of the index patients carried rare variants, such as KCNE1 p.D85N, KCNQ1 p.P448R, SCN5A p.A572D, SCN5A p.S1103Y, and SCN5A p.R1193Q. The possible effect of these missense variants is difficult to interpret and they are referred to in the literature as both mutations and functional polymorphisms $[44,45]$. Although these variants might contribute to the phenotype, we did not consider these as disease-causing mutations by themselves, since careful interpretation of genetic test results is critical in clinical practice [43].

\section{Limitations of the study}

The 200 index cases were almost consecutively included; we have excluded 27 index cases with other diagnoses such as Jervell and Lange-Nielsen syndrome, Brugada Syndrome, short QT syndrome, and healthy individuals sent for LQTS-screening due to a history of first-degree relative with SUD. No selection of the patients was performed, resulting in a cohort that ranges from low suspicion of LQTS to high. Since the patients were referred for LQTS screening in ordinary health care, the clinical data were collected retrospectively and is thus not complete for all families. Only 23 of 105 exons (8-15, $44-50,83,88-105)$ of the gene RYR2 were analysed. DNA was not available for screening of all five genes in some of the individuals, and therefore it is possible that some double mutations might have been missed. Due to the lack of DNA, there were incomplete analyses of the $K C N Q 1$ gene in three individuals, in the $K C N H 2$ gene in two, KCNE1 in five, KCNE2 gene in four, and in the SCN5A gene in nine individuals. For the same reason MLPA was not performed in two cases.

\section{Conclusions}

The distribution of mutations between the different genes, as well as the type of mutation, concur with findings of other LQTS population surveys. In contrast, the mutation panorama in this Swedish cohort is characterised by two founder mutations in the KCNQ1 gene that accounts for one-fourth of the identified mutations. The findings of a mutation in RYR 2 among $8 \%$ of the selected cases, as well as CNVs among $2 \%$ of all genotype-negative cases suggest that mutation analysis of RYR2 and MLPA analysis in a genotype-negative LQTS population is of importance and might give a higher yield than screening of the less common LQTSassociated genes.

\section{Additional files}

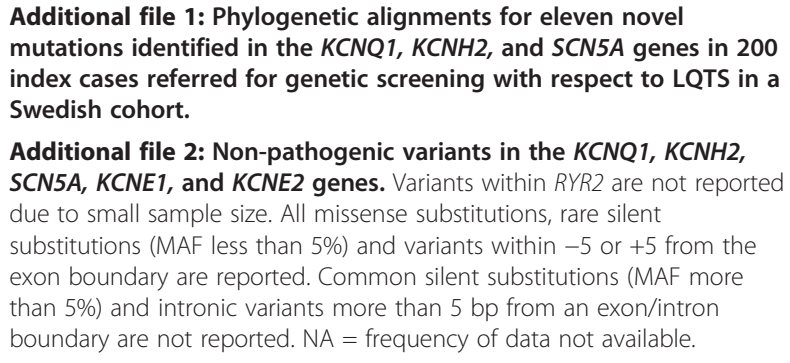

Additional file 1: Phylogenetic alignments for eleven nove mutations identified in the KCNQ1, KCNH2, and SCN5A genes in 200 index cases referred for genetic screening with respect to LQTS in a Swedish cohort.

Additional file 2: Non-pathogenic variants in the KCNQ1, KCNH2, SCN5A, KCNE1, and KCNE2 genes. Variants within RYR2 are not reported due to small sample size. All missense substitutions, rare silent substitutions (MAF less than $5 \%$ ) and variants within -5 or +5 from the exon boundary are reported. Common silent substitutions (MAF more than $5 \%$ ) and intronic variants more than $5 \mathrm{bp}$ from an exon/intron boundary are not reported. NA = frequency of data not available.

\section{Abbreviations}

CNV: Copy Number Variations; CPVT: Catecholaminergic Polymorphic Ventricular Tachycardia; DHPLC: Denaturing High-Performance Liquid Chromatography; DNA: Deoxyribonucleic Acid, ECG, Electrocardiogram; HGVS: Human Genome Variation Society; LQTS: Long QT syndrome; MLPA: Multiplex Ligation-dependent Probe Amplification; PCR: Polymerase Chain Reaction; SCD: Sudden Cardiac Death; TdP: Torsade-de-Pointes; VUS: Variants of Uncertain Significance.

\section{Competing interests}

The authors declare that they have no competing interests. 


\section{Authors' contributions}

ELS: conception and design, acquisition of data, analysis, interpretation of data, drafting the manuscript. IMB: carried out most of the molecular genetic studies, analysis, interpretation of data and revision of manuscript. KC, JJ: analysis, interpretation of data and revision of manuscript. BAJ: analysis, interpretation of data. AW, UBD: analysis and revision of manuscript. AN, SJ, AR: conception and design, analysis and revision of manuscript. All authors read and approved the final manuscript.

\section{Acknowledgements}

This research was supported by grants from the medical faculty at Umeå University and the Swedish heart-lung foundation. We thank all the referring physicians for contribution of phenotypic data and samples. We also thank all patients and family members who have donated the samples that made this study possible. All mutational analyses performed in this study were conducted as part of ordinary health care.

\section{Author details}

'Department of Medical Biosciences, Medical and Clinical Genetics, Umeå University, Umeå, Sweden. ${ }^{2}$ Department of Clinical Sciences, Paediatrics, Umeå University, Umeå, Sweden. ${ }^{3}$ Heart Centre and Department of Public Health and Clinical Medicine, Umeå University, Umeå, Sweden.

Received: 28 June 2012 Accepted: 10 October 2012

Published: 25 October 2012

\section{References}

1. Goldenberg I, Zareba W, Moss AJ: Long QT Syndrome. Curr Prob/ Cardiol 2008, 33(11):629-694.

2. Kramer DB, Zimetbaum PJ: Long-QT syndrome. Cardiol Rev 2011, 19(5):217-225

3. Ackerman MJ: The long QT syndrome: ion channel diseases of the heart Mayo Clin Proc 1998, 73(3):250-269.

4. Priori SG, Schwartz PJ, Napolitano C, Bloise R, Ronchetti E, Grillo M, Vicentini A, Spazzolini C, Nastoli J, Bottelli G, et al: Risk stratification in the long-QT syndrome. N Engl J Med 2003, 348(19):1866-1874.

5. Schwartz PJ, Priori SG, Spazzolini C, Moss AJ, Vincent GM, Napolitano C, Denjoy I, Guicheney P, Breithardt G, Keating MT, et al: Genotype-phenotype correlation in the long-QT syndrome: gene-specific triggers for life-threatening arrhythmias. Circulation 2001, 103(1):89-95.

6. Wilde AA, Jongbloed RJ, Doevendans PA, Duren DR, Hauer RN, van Langen IM, van Tintelen JP, Smeets HJ, Meyer H, Geelen JL: Auditory stimuli as a trigger for arrhythmic events differentiate HERG-related (LQTS2) patients from KVLQT1-related patients (LQTS1). J Am Coll Cardiol 1999, 33(2):327-332.

7. Priori SG, Napolitano C, Memmi M, Colombi B, Drago F, Gasparini M DeSimone L, Coltorti F, Bloise R, Keegan R, et al: Clinical and molecular characterization of patients with catecholaminergic polymorphic ventricular tachycardia. Circulation 2002, 106(1):69-74.

8. Berge KE, Haugaa KH, Fruh A, Anfinsen OG, Gjesdal K, Siem G, Oyen N, Greve G, Carlsson A, Rognum TO, et al: Molecular genetic analysis of long QT syndrome in Norway indicating a high prevalence of heterozygous mutation carriers. Scand J Clin Lab Invest 2008, 68(5):362-368.

9. Tester DJ, Kopplin $\sqcup$, Will ML, Ackerman MJ: Spectrum and prevalence of cardiac ryanodine receptor (RyR2) mutations in a cohort of unrelated patients referred explicitly for long QT syndrome genetic testing. Hear Rhythm 2005, 2(10):1099-1105.

10. Roden DM: Clinical practice. Long-QT syndrome. N Engl J Med 2008, 358(2):169-176

11. Bokil NJ, Baisden JM, Radford DJ, Summers KM: Molecular genetics of long QT syndrome. Mol Genet Metab 2010, 101(1):1-8.

12. Splawski I, Shen J, Timothy KW, Lehmann MH, Priori S, Robinson JL, Moss AJ, Schwartz PJ, Towbin JA, Vincent GM, et al: Spectrum of mutations in longQT syndrome genes. KVLQT1, HERG, SCN5A, KCNE1, and KCNE2. Circulation 2000, 102(10):1178-1185.

13. Tester DJ, Will ML, Haglund CM, Ackerman MJ: Compendium of cardiac channel mutations in 541 consecutive unrelated patients referred for long QT syndrome genetic testing. Hear Rhythm 2005, 2(5):507-517.

14. Kapplinger JD, Tester DJ, Alders M, Benito B, Berthet M, Brugada J, Brugada P, Fressart V, Guerchicoff A, Harris-Kerr C, et al: An international compendium of mutations in the SCN5A-encoded cardiac sodium channel in patients referred for Brugada syndrome genetic testing. Hear Rhythm 2010, 7(1):33-46.

15. Napolitano C, Priori SG, Schwartz PJ, Bloise R, Ronchetti E, Nastoli J, Bottelli $G$, Cerrone M, Leonardi S: Genetic testing in the long QT syndrome: development and validation of an efficient approach to genotyping in clinical practice. JAMA 2005, 294(23):2975-2980.

16. Tranebjaerg L, Bathen J, Tyson J, Bitner-Glindzicz M: Jervell and Lange-Nielsen syndrome: a Norwegian perspective. Am J Med Genet 1999, 89(3):137-146

17. Fodstad H, Swan H, Laitinen P, Piippo K, Paavonen K, Viitasalo M, Toivonen $L$, Kontula K: Four potassium channel mutations account for $73 \%$ of the genetic spectrum underlying long-QT syndrome (LQTS) and provide evidence for a strong founder effect in Finland. Ann Med 2004, 36(Suppl 1):53-63.

18. Crotti L, Spazzolini C, Schwartz PJ, Shimizu W, Denjoy I, Schulze-Bahr E, Zaklyazminskaya EV, Swan H, Ackerman MJ, Moss AJ, et al: The common long-QT syndrome mutation KCNQ1/A341V causes unusually severe clinical manifestations in patients with different ethnic backgrounds: toward a mutation-specific risk stratification. Circulation 2007, 116(21):2366-2375

19. Itoh H, Shimizu W, Hayashi K, Yamagata K, Sakaguchi T, Ohno S, Makiyama T, Akao M, Ai T, Noda T, et al: Long QT syndrome with compound mutations is associated with a more severe phenotype: a Japanese multicenter study. Hear Rhythm 2010, 7(10):1411-1418.

20. Kapa S, Tester DJ, Salisbury BA, Harris-Kerr C, Pungliya MS, Alders M, Wilde $A A$, Ackerman MJ: Genetic testing for long-QT syndrome: distinguishing pathogenic mutations from benign variants. Circulation 2009, 120(18):1752-1760.

21. Antonarakis SE: Recommendations for a nomenclature system for human gene mutations. Nomenclature Working Group. Hum Mutat 1998, 11(1):1-3.

22. Kumar P, Henikoff S, Ng PC: Predicting the effects of coding nonsynonymous variants on protein function using the SIFT algorithm. Nat Protoc 2009, 4(7):1073-1081.

23. Sunyaev S, Ramensky V, Koch I, Lathe W 3rd, Kondrashov AS, Bork P: Prediction of deleterious human alleles. Hum Mol Genet 2001, 10(6):591-597.

24. Petitjean A, Mathe E, Kato S, Ishioka C, Tavtigian SV, Hainaut P, Olivier M: Impact of mutant p53 functional properties on TP53 mutation patterns and tumor phenotype: lessons from recent developments in the IARC TP53 database. Hum Mutat 2007, 28(6):622-629.

25. Benson DW, Wang DW, Dyment M, Knilans TK, Fish FA, Strieper MJ, Rhodes $\mathrm{TH}$, George AL Jr: Congenital sick sinus syndrome caused by recessive mutations in the cardiac sodium channel gene (SCN5A). J Clin Invest 2003, 112(7):1019-1028.

26. Winbo A, Diamant UB, Rydberg A, Persson J, Jensen SM, Stattin EL: Origin of the Swedish long QT syndrome Y111C/KCNQ1 founder mutation. Hear Rhythm 2011, 8(4):541-547.

27. Jespersen T, Rasmussen HB, Grunnet M, Jensen HS, Angelo K, Dupuis DS, Vogel LK, Jorgensen NK, Klaerke DA, Olesen SP: Basolateral localisation of KCNQ1 potassium channels in MDCK cells: molecular identification of an N-terminal targeting motif. J Cell Sci 2004, 117(Pt 19):4517-4526.

28. Dahimene S, Alcolea S, Naud P, Jourdon P, Escande D, Brasseur R, Thomas A, Baro I, Merot J: The N-terminal juxtamembranous domain of KCNQ1 is critical for channel surface expression: implications in the Romano-Ward LQT1 syndrome. Circ Res 2006, 99(10):1076-1083.

29. Winbo A, Diamant UB, Stattin EL, Jensen SM, Rydberg A: Low incidence of sudden cardiac death in a Swedish Y111C type 1 long-QT syndrome population. Circ Cardiovasc Genet 2009, 2(6):558-564.

30. Amin AS, Giudicessi JR, Tijsen AJ, Spanjaart AM, Reckman YJ, Klemens CA, Tanck MW, Kapplinger JD, Hofman N, Sinner MF, et al: Variants in the 3' untranslated region of the KCNQ1-encoded Kv7.1 potassium channel modify disease severity in patients with type 1 long QT syndrome in an allele-specific manner. Eur Heart J 2012, 33(6):714-723.

31. Olsson M, Norgren N, Obayashi K, Plante-Bordeneuve V, Suhr OB, Cederquist $\mathrm{K}$, Jonasson J: A possible role for miRNA silencing in disease phenotype variation in Swedish transthyretin V30M carriers. BMC Med Genet 2010, 11:130.

32. Wei J, Fish FA, Myerburg RJ, Roden DM, George AL Jr: Novel KCNQ1 mutations associated with recessive and dominant congenital long QT syndromes: evidence for variable hearing phenotype associated with R518X. Hum Mutat 2000, 15(4):387-388. 
33. Larsen LA, Fosdal I, Andersen PS, Kanters JK, Vuust J, Wettrell G, Christiansen M: Recessive Romano-Ward syndrome associated with compound heterozygosity for two mutations in the KVLQT1 gene. Eur J Hum Genet 1999, 7(6):724-728

34. Winbo A, Stattin EL, Diamant UB, Persson J, Jensen SM, Rydberg A: Prevalence, mutation spectrum, and cardiac phenotype of the Jervell and Lange-Nielsen syndrome in Sweden. Europace 2012, [Epub ahed of print].

35. Marjamaa A, Salomaa V, Newton-Cheh C, Porthan K, Reunanen A, Karanko $H$, Jula A, Lahermo $P$, Vaananen $H$, Toivonen $L$, et al: High prevalence of four long QT syndrome founder mutations in the Finnish population. Ann Med 2009, 41(3):234-240.

36. Medeiros-Domingo A, Bhuiyan ZA, Tester DJ, Hofman N, Bikker $\mathrm{H}$, van Tintelen JP, Mannens MM, Wilde AA, Ackerman MJ: The RYR2-encoded ryanodine receptor/calcium release channel in patients diagnosed previously with either catecholaminergic polymorphic ventricular tachycardia or genotype negative, exercise-induced long QT syndrome: a comprehensive open reading frame mutational analysis. J Am Coll Cardiol 2009, 54(22):2065-2074.

37. Koopmann TT, Alders M, Jongbloed RJ, Guerrero S, Mannens MM, Wilde AA, Bezzina CR: Long QT syndrome caused by a large duplication in the KCNH2 (HERG) gene undetectable by current polymerase chain reactionbased exon-scanning methodologies. Hear Rhythm 2006, 3(1):52-55.

38. Eddy CA, MacCormick JM, Chung SK, Crawford JR, Love DR, Rees MI, Skinner $J R$, Shelling AN: Identification of large gene deletions and duplications in KCNQ1 and KCNH2 in patients with long QT syndrome. Hear Rhythm 2008, 5(9):1275-1281.

39. Barc J, Briec F, Schmitt S, Kyndt F, Le Cunff M, Baron E, Vieyres C, Sacher F, Redon R, Le Caignec $C$, et al: Screening for copy number variation in genes associated with the long QT syndrome: clinical relevance. J Am Coll Cardiol 2011, 57(1):40-47.

40. Tester DJ, Benton AJ, Train L, Deal B, Baudhuin LM, Ackerman MJ: Prevalence and spectrum of large deletions or duplications in the major long QT syndrome-susceptibility genes and implications for long QT syndrome genetic testing. Am J Cardiol 2010, 106(8):1124-1128.

41. Imboden M, Swan H, Denjoy I, Van Langen IM, Latinen-Forsblom PJ, Napolitano C, Fressart V, Breithardt G, Berthet M, Priori S, et al: Female predominance and transmission distortion in the long-QT syndrome. N Engl J Med 2006, 355(26):2744-2751.

42. Westenskow P, Splawski I, Timothy KW, Keating MT, Sanguinetti MC: Compound mutations: a common cause of severe long-QT syndrome. Circulation 2004, 109(15):1834-1841.

43. Refsgaard L, Holst AG, Sadjadieh G, Haunso S, Nielsen JB, Olesen MS: High prevalence of genetic variants previously associated with LQT syndrome in new exome data. Eur J Hum Genet 2012, 20:905-908.

44. Tester DJ, Valdivia C, Harris-Kerr C, Alders M, Salisbury BA, Wilde AA, Makielski JC, Ackerman MJ: Epidemiologic, molecular, and functional evidence suggest A572D-SCN5A should not be considered an independent LQT3-susceptibility mutation. Hear Rhythm 2010, 7(7):912-919.

45. Van Norstrand DW, Tester DJ, Ackerman MJ: Overrepresentation of the proarrhythmic, sudden death predisposing sodium channel polymorphism $\mathrm{S1103Y}$ in a population-based cohort of African-American sudden infant death syndrome. Hear Rhythm 2008, 5(5):712-715. 